\title{
Unplanned urbanization and canopy losses in Indian Punjab
}

\begin{abstract}
Urbanization, the increase in concrete areas in cities, has lead to alternation in land use patterns across the globe. This expansion of concrete regions in the cities has mainly impacted the canopy cover in the regions. Those regions of the earth that were once inhabited by the trees have now got turned into the concrete floors of cities. Despite the fact that forested land is critical for a healthy ecosystem, trees are being cut without appropriate concern and consideration. The Indian state of Punjab is undergoing through a heavy load of unplanned urbanization that has lead to serious canopy losses in the state. Had the state been a rich in forested land, it would not have had demanded serious attention. However, Punjab is no longer known to be rich in canopy cover. It is the state with the minimum forest cover in the country that counts to almost $3.5 \%$ of its $50362 \mathrm{sq} \mathrm{Kms}$ of area or even lesser with continued deforestation in the name of development. The state lost 9lakh trees between 2011 and 2017 while reforestation and afforestation has taken up the back seat during these years. As the tree cutting continues in the state, this percentage is approaching even a smaller value with each passing day. With this small canopy cover and a population of 28 million to support, the state has already started observing some of the disastrous consequences of unplanned urbanization and canopy losses; be it depleting water table, changes in weather patterns, unhealthy air or water scarcity. This article reviews the alarming bells that unsustainable development at the cost of forested land has begun to ring for the imbalance in nature that reduced forest cover has started to generate in the state of Punjab.
\end{abstract}

Volume 4 Issue 2 - 2019

\author{
Kirandeep K Dhami \\ Department of Botanical \& Environmental Sciences, Guru \\ Nanak Dev University, India
}

Correspondence: Dr. Kirandeep K Dhami, Department of Botanical \& Environmental Sciences, Guru Nanak Dev University,Amritsar, India, Email kirandeepdhami@gmail.com

Received: February 13, 2019 | Published: April 03, 2019

\section{Introduction}

Urbanization is an irreversible land use transformation from traditional rural structure to modern industrialized units in which a sharp shift away from agriculture is apparent. This land use transformation apparently is an economically beneficial option for many in the population; however it is disastrous to the environment. Propagating unplanned urbanization can lead to unavailability of pure air and water supply to its residents. A minimum of 33\% canopy cover is necessary to ensure adequate oxygen to its citizens. Any reductions below this level for unsustainable unplanned urbanization can take away the access to basic amenities of life. Hence, a balance between the concretization of floors and vegetative cover is a must for the health and wellbeing of environment and human beings. ${ }^{1}$

Vegetative cover is an important component of the earth that makes the planet earth habitable for various species by providing clean air and water to all the living beings. Trees are the "lungs of the earth" that regulate the composition of air in the atmosphere by consuming carbon dioxide and producing oxygen. Every acre of vegetative cover can produce almost 6 tons of oxygen every year. Not only it produces oxygen that is necessary for survival for many species, it also absorbs carbon dioxide, one of major greenhouse gases, through the process of photosynthesis. Therefore, vegetation efficiently moderates the greenhouse effect by regulating the concentration of carbon dioxide. Also, vegetation prevents soil erosion and act as hydrologic flow modulator allowing the water to percolate through the pores in soil and purify before reaching to the aquifers down in the earth. Despite various economic or ecological benefits that vegetation bring, the earth is losing its canopy cover at an alarming rate owing to pressures of increasing populations, urbanization and development. ${ }^{2}$
Vegetation covered one half of the earth's surface at one point of time in the earth's history, however it covers only one third or even lesser of the earth's surface at present. This decline in vegetative cover has appeared for various reasons in which population explosion and urbanization are the major ones. India has lost large areas of vegetative cover to urbanization left with only $24.39 \%$ of the total geographical area against a minimum requirement of atleast $33 \%$ of total geographical area under National Forest Policy. ${ }^{3}$ Among all the twenty nine states in the country, the state of Punjab has the minimum canopy cover that makes hardly $3.65 \%$ of total geographical area of the state or even lesser with continued deforestation. ${ }^{4}$ This article discusses the state of vegetative cover in small north western state of Punjab and the ecological disasters that the state is currently facing for the massive losses of canopy cover in the state.

\section{Punjab \& its state of canopy cover}

Punjab, a north western state of India (Figure 1) that forms a part of Indo-Gangetic alluvial plain, is composed of sediments of Shiwalik hills and Himalayas which are brought down and laid by the rivers of Indus system. The state experiences mainly three different seasons annually [Winter Season (November to March), summer season (April to June) and Monsoon season (July to September)] during which the temperature observes a large variation between 45 degree centigrade to below zero degree centigrade. The average rainfall in the state is about $480-960 \mathrm{~mm}$ every year. Historically, the state of Punjab has been viewed as a combination of three different regions, Majha (Amritsar, Gurdaspur, Tarn Taran, and Pathankot), Doaba (Jalandhar, Kapurthala, Nawashahr and Hoshiarpur) and Malwa (Ludhiana, Patiala, Sangrur etc.) that were divided by rivers. 


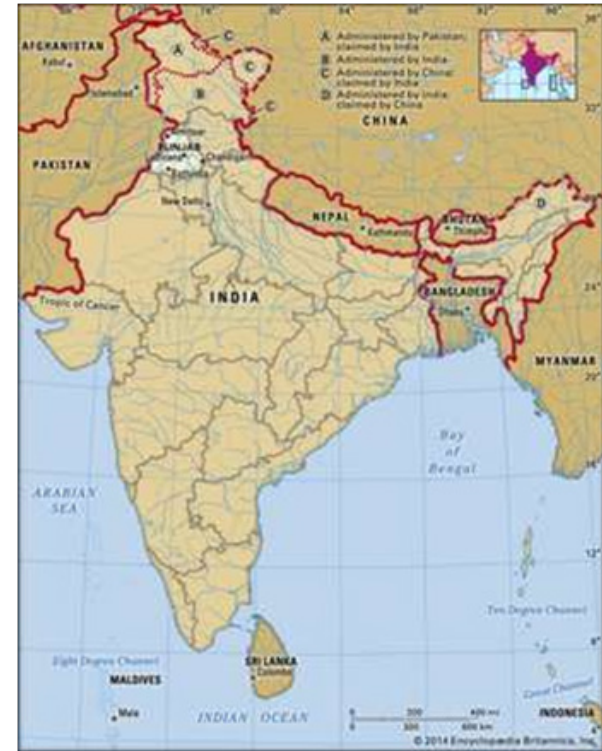

Figure I Punjab, a north western state of India $\left(31.147 I^{\circ} \mathrm{N}, 75.34 I 2^{\circ} \mathrm{E}\right)$ on Indian Map.
The major categories of forest that are found in Punjab include mainly dry deciduous forests found in all three Majha, Malwa and Doaba regions. The dry deciduous forests are those forests that are found under moderate cool climates with moderate rainfall. The broad leaves of trees are shed in particular season so that the tree can conserve the loss of moisture through transpiration. Bir forests are found in Patiala and Sangrur districts whereas Mand forests are found in Tarn Taran, Kapurthala and Rup Nagar districts. Shivalik forest that constitutes more than $70 \%$ of total forest area of the state is found in Hoshiarpur, Gurdaspur and Pathankot, and Ropar districts of Punjab (Table 1).

Punjab is that one of the important states of the India that has minimum forest cover in India. Based on the satellite data, the total forest cover in the state has contracted merely to $1837 \mathrm{Sq} \mathrm{Kms}$ which makes $3.65 \%$ of the total geographical area of the state $(50362 \mathrm{sq}$ $\mathrm{Kms}$ ). Only two districts in the state, Patiala and Amritsar, have been recorded to have very dense forests that cover an area of $8 \mathrm{Sq} \mathrm{Kms.}$ Hardly $806 \mathrm{Sq} \mathrm{Kms}$ area of the state comes under moderately dense forest and $1023 \mathrm{Sq} \mathrm{Kms} \mathrm{under} \mathrm{open} \mathrm{forest} \mathrm{(State} \mathrm{of} \mathrm{Forest} \mathrm{Report,}$ 2017) (Table 2). The data is clearly evident of very small vegetative cover that has left over the state of Punjab and the scientific community is worried over its repercussion in the coming years.

Table I Champion and Seth Classification of forest cover in Punjab

\begin{tabular}{|c|c|c|}
\hline S.No & Forest type & Vegetation \\
\hline I & Northern Dry Deciduous Mixed & Acacia catechu, A. nilotica, A. leucophloea and Anogeissus latifolia, Carissa opaca, Grevia optiva, Adatoda vasica, etc. \\
\hline 2 & Dry Deciduous Scrub Forests & $\begin{array}{l}\text { Found in Kandi tract with predominant species like Acacia catechu, Dalbergia sissoo, Bombax ceiba, Emblica } \\
\text { officinalis, Lannea grandis, Toona ciliata, Cassia fistula, etc. }\end{array}$ \\
\hline 3 & Khair, Sissoo, Bela and Mand & Khair, Sissoo, Mangoes, Eucalypus \\
\hline 4 & Shivalik Chir Pine Forests & $\begin{array}{l}\text { Pinus roxburghii, Terminalia alata, Terminalia bellerica, Terminalia chebula, Anogeisus latifolia, Emblica officinalis, } \\
\text { Cassia fistula, etc. }\end{array}$ \\
\hline 5 & Dry Deciduous Bamboo Forests & $\begin{array}{l}\text { Found in Dasua Forest Division only. The main species found in these forests is Dendrocalamus strictus. The } \\
\text { other associates are Lannea grandis, Diospyros montana, Butea monosperma, Holoptelia integrifolia and Cassia } \\
\text { fistula. }\end{array}$ \\
\hline
\end{tabular}

Table 2 Vegetative Cover in different districts of Punjab

\begin{tabular}{|c|c|c|c|c|c|c|c|}
\hline S.No & Districts & $\begin{array}{l}\text { Geographical } \\
\text { Area }\end{array}$ & $\begin{array}{l}\text { Very Dense } \\
\text { Forests }\end{array}$ & $\begin{array}{l}\text { Mod. Dense } \\
\text { Forests }\end{array}$ & $\begin{array}{l}\text { Open } \\
\text { Forests }\end{array}$ & Total & $\begin{array}{l}\text { Percentage of } \\
\text { geographical area }\end{array}$ \\
\hline I & Amritsar & 2683 & I & 12 & 14 & 27 & I.0I \\
\hline 2 & Barnala & 2414 & & I & 7 & 8 & 0.33 \\
\hline 3 & Bathinda & 3353 & & 19 & 37 & 56 & 1.67 \\
\hline 4 & Faridkot & 1458 & & 4 & 17 & 21 & $\mathrm{I} .44$ \\
\hline 5 & Fatehgarh Sahib & 1180 & & 4 & 0 & 4 & 0.34 \\
\hline 6 & Firozpur & 5305 & & 6 & 28 & 34 & 0.64 \\
\hline 7 & Gurdaspur & 2242 & & 105 & 108 & 213 & 9.5 \\
\hline 8 & Hoshiarpur & 3551 & & 371 & 354 & 725 & 20.42 \\
\hline 9 & Jalandhar & 3386 & & 2 & 9 & II & 0.32 \\
\hline II & Ludhiana & 1633 & & 26 & 29 & 55 & 3.37 \\
\hline 12 & Mansa & 3578 & & I & 9 & 10 & 0.28 \\
\hline 13 & Moga & 2198 & & 0 & 9 & 9 & 0.41 \\
\hline 14 & Muktsar & 2593 & & 6 & 12 & 18 & 0.69 \\
\hline
\end{tabular}


Table Continued....

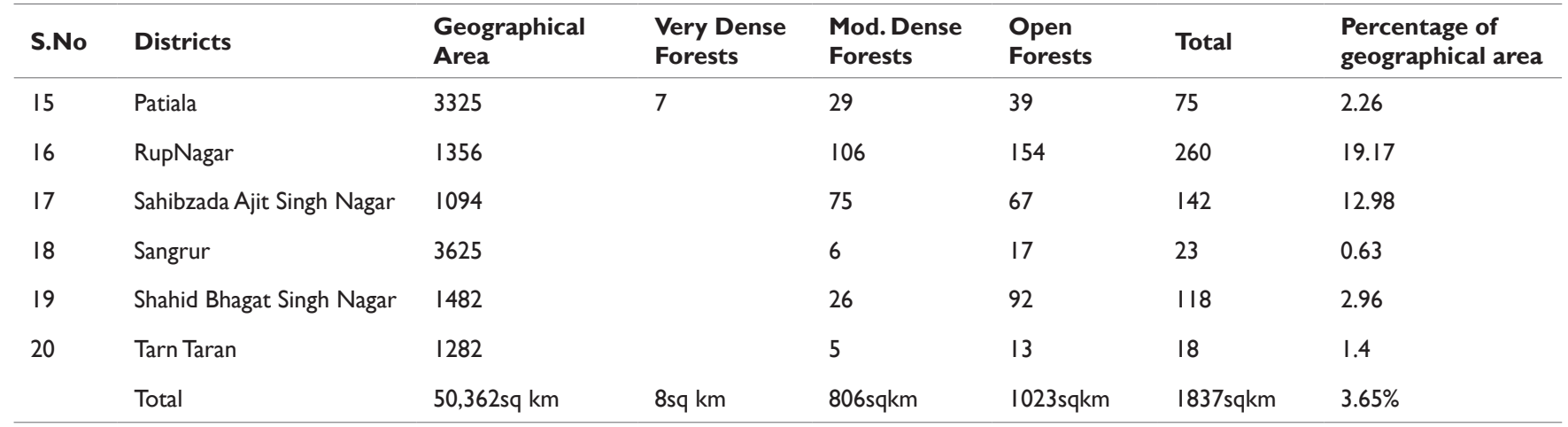

\section{Declining vegetative cover and the consequences}

The state of Punjab is losing its vegetative cover at an alarming rate. It has happened really at a very fast rate in recent past a few years. A predominantly agricultural state is on the track of becoming a completely urbanized state with massive destruction done to its ecology. Currently, the state of Punjab that has a geographical area of $50,362 \mathrm{Sq} \mathrm{Kms}$ is left with only $1771 \mathrm{Sq} \mathrm{Kms}$ of forest cover that does not include any very dense forest. Mostly, the state is left with $103 \mathrm{Sq}$ $\mathrm{Kms}$ of open forest and $735 \mathrm{Sq} \mathrm{Kms}$ of moderately dense forest. About 48,554Sq Kms of the region in the state is either urbanized world or lies in a non-vegetated state (Forest Survey of India, 2015) (Figure 2). In other words, $96.5 \%$ of the area in the state is not under the vegetative cover. A total of 9Lakh trees have been axed in the state during last eight years since 2011 (Table 3) to carry out various developmental projects; build roads, homes and industries. The growing population in the state has changed its land cover usage in the state from a forested farmland to concrete floors only. Irrespective of all the developmental activities or population pressures, the biggest reason that has apparently lead to such a grim situation in the state is apparently a general lack of concern and interest in the society towards vegetative cover. The devastation of deforestation is expected to be huge in the coming years not only for future generations but in general for the whole society.

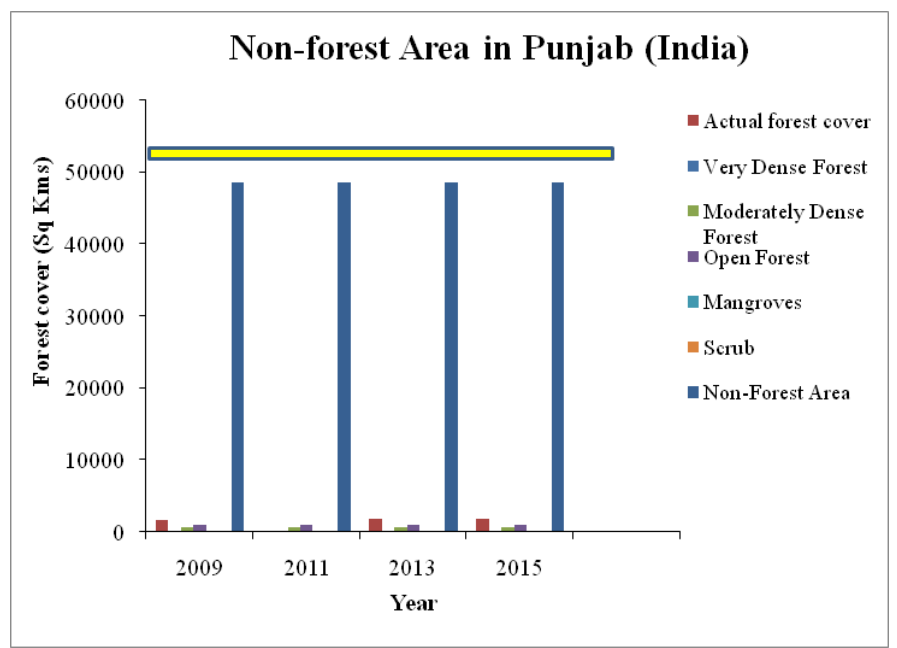

Figure 2 A comparison of Non-forested (Blue Bars) and forested land (all other colors) in the state over a span of seven years since 2009. The closeness between the tip of the blue bars and yellow horizontal bar that shows the overall geographical area of the state is indicative of a very small forest cover remaining in the state.
Table 3 Year-wise deforestation in the state of Punjab

\begin{tabular}{ll}
\hline Year & Tree felled \\
\hline $2011-2012$ & 75,000 \\
$2012-2013$ & I.92Lakh \\
$2013-2014$ & 2.4 Lakh \\
$2014-2015$ & 2.12Lakh \\
$2015-2016$ & I.89Lakh \\
& Total=9Lakh
\end{tabular}

The state has already started to observe some of the most dramatic impacts this change in land usage. Among those, changing weather patterns and depleting water tables are the major ones. The state has already entered into that phase where preliminary effects can be seen. The climate data indicates that the maximum and minimum temperatures have increased as compared to the baseline of 19712000 in the state. The data and projections clearly indicate a rise in minimum temperatures and a projected increase in temperature in the short term between 2021 and 2050..$^{5,6}$ This increase in overall temperatures in the state can be attributed to the massive losses in vegetative cover, and urbanization. The concrete floors of urbanized world preserve heat very well causing warmth in the air and rise in temperatures while vegetative cover helps in maintaining cool in the atmosphere by blocking sunrays and providing shade. With small forest cover and higher levels of carbon dioxide in the atmosphere, an increased speed and severity of global warming is no surprise. The comparison of reports between 2015 and 2016 clearly showed that water levels in $65 \%$ of the wells declined in the $67 \%$ of area of Punjab. The studies conducted by Central Ground Water Board (CGWB) in 2017 showed a decline in water in 89 per cent of the observation wells. The report also revealed that water table fell by $2-4$ meters in $26 \%$ area of state and upto 2 meters in $60 \%$ of the state. Another dramatic impact the state is expected to observe for the lack of tree cover on its grounds is the loss of species. Eighty percent of Earth's land animals and plants live in forests, and depend on vegetation cover for survival. Several are unable to survive when their habitat is destroyed. Some of such consequences the state of Punjab is already observing. Northern Goshawk, "Baaz", the state bird that is known as a symbol of strength and tenacity, is no longer seen in any zoo, aviary or sanctuary of the state. There has been no recent sighting of this migratory bird. Similarly, House sparrows that were used to be common in the houses of Punjab almost twenty years ago have vanished. They are no longer commonly seen in the state. 


\section{Conclusion}

Development and urbanization at the cost of massive losses in vegetative cover is causing a huge change in the land use pattern in the state of Punjab. The dangers of heat, warmth, drought, water scarcity and loss in species are eminent in the near future. Some of the devastating impacts have started to show its colour at present too. The situation is grim in Punjab with the state under least vegetative cover in the country. In such a scenario, massive afforestation is the only solution to balance the urbanization and a huge deforestation in the state. Considering the depth of this alarming situation, it becomes the responsibility of every resident of the state to begin understand the value of this natural treasure and take necessary steps towards protection of remaining vegetative cover and take all necessary measures of increase the same. If every citizen of a populated state can take the responsibility of growing only a single tree, the state can get rewarded with atleast 28 million trees in a few years putting a hold on the rising issues of global warming, drought, water scarcity and species extinction.

\section{Acknowledgments}

None.

\section{Conflicts of interest}

The authors declare that there is no conflict of interest regarding the publication of this article.

\section{References}

1. Champion HG, Seth SK. A Revised survey of the forest types of India. Deli: Government of India Press; 1968. 600 p

2. Cajander AL. Forest types and their significance. Acta Forestalia Fennica. 1949:56-71.

3. National Forest Policy. Ministry of Environment, Forests and Climate Change. Government of India; 2018.

4. State of Forest Report. Forest Survey of India: Ministry of Environment and Forest, India. 2017.

5. Neelima J, Ladhar Satnam S, Simrandeep K, et al. Punjab State action plan on climate change. Punjab State Council for Science and Technology and GIZ; 2014. 329 p.

6. van Oldenborgh G J, Philip S, Kew S, et al. Extreme heat in India and anthropogenic climate change. Nat Hazards Earth Syst Sci. 2018;18:365381. 